\title{
Studi Kasus Tentang Bunuh Diri di Gunung Kidul: Antara Realitas dan Mitos Pulung Gantung
}

\author{
Tatag Maulana Ali ${ }^{1}$, Aloysius L.S. Soesilo ${ }^{2}$ \\ 1,2Fakultas Psikologis Universitas Kristen Satya Wacana \\ Jl. Diponegoro 52-60 Salatiga \\ 1tatagmaulana1234@gmail.com \\ 2alsoes16@gmail.com
}

\begin{abstract}
The rate of suicide case in Indonesia especially in Gunung Kidul is still high. The case is regarding to a phenomenon of Pulung Gantung which have been believed hereditary by society of Gunung Kidul. This study investigates experiences and perceptions of Pulung Gantung towards participants who have been saved from efforts of suicide and who are involved directly to attempt relief efforts. This study uses a qualitative method with an approach of phenomenology-study. This study observes four (4) participants who consist of 2 criteria; the first one is an occupant of Gunung Kidul who had ever undergone suicide efforts. Then, the next participants are two Gunung Kidul accupants whose ages are 42 and 40 years old, and have been lived in Gunung Kidul for 25 years more. The findings of the study show that, before the participant did suicide by hanging, he had problems or a chronic disease which could not come to end. Later, he got a dream or a suicide calling, intemperance when he did suicide by hanging. After the efforts, he underwent several changes and be able to do some activities. He did not believe that his suicide effort is caused by Pulung Gantung. Future studies are expected to contribute more participants who have different problem to utilize the accuracy of the data. Then, the secondary data of this study towards Pulung Gantung culture has not itemized enough.
\end{abstract}

Keywords: Gunung Kidul, Pulung Gantung, suicide, suicide by hanging, myth, reality, psychological causes and consequences

\begin{abstract}
Abstrak. Kasus bunuh diri di Indonesia terkhusus Gunung Kidul masih cukup tinggi. Kasus bunuh diri di Gunung Kidul tersebut tidak terlepas dari fenomena Pulung Gantung yang sudah dipercayai turun temurun oleh masyarakat Gunung Kidul. Penelitian ini bertujuan meneliti pengalaman dan persepsi tentang Pulung Gantung pada partisipan yang pernah selamat dari upaya bunuh diri serta dari partisipan lain yang terlibat langsung dalam upaya pertolongan. Penelitian ini menggunakan metode kualitatif dengan pendekatan fenomenologis-studi kasus. Peengumpulan data menggunakan observasi dan wawancara. Penelitian ini menggunakan empat (4) partisipan yang terdiri dari 2 kriteria. kriteria pertama adalah warga Gunung Kidul yang pernah melakukan percobaan bunuh diri akibat pengaruh budaya Pulung Gantung. Partisipan kriteria kedua adalah dua orang warga Gunung Kidul yang masing-masing berumur 42 tahun dan 40 tahun serta sudah lebih dari 25 tahun hidup di Gunung Kidul. Temuan penelitian ini menunjukkan bahwa sebelum partisipan melakukan upaya gantung diri, partisipan memiliki masalah atau penyakit menahun yang tidak dapat diselesaikan, kemudian mendapat mimpi atau ajakan bunuh diri, serta hilangnya kesadaran ketika melakukan upaya gantung diri. Pasca upaya gantung dirinya partisipan mengalami beberapa perubahan dan dapat kembali beraktivas, dan timbul rasa tidak percaya terhadap penyebab upaya gantung dirinya disebabkan oleh Pulung Gantung. Penelitian lebih lanjut agar menambah jumlah partisipan yang memiliki masalah yang berbeda untuk menambah kedalaman data. Selain itu, data sekunder yang didapatkan oleh penulis mengenai budaya Pulung Gantung belum cukup mendalam.
\end{abstract}

Kata kunci: Gunung Kidul, Pulung Gantung, bunuh diri, gantung diri, mitos, realita. 


\section{Pendahuluan}

Pada 17 Maret 2017, seantero Facebook dibuat geger oleh aksi gantung diri yang dilakukan Pahinggar Ndrawan lewat siaran langsung di akun Facebook pribadinya. Videonya ini pun, sempat tayang setidaknya hingga 10 jam, sampai akhirnya dihapus oleh pihak Facebook.

Pria 35 tahun yang akrab disapa Indra itu, sempat bercerita dan menyampaikan keluh kesahnya di akun Facebook pribadinya. Indra mengaku, bahwa ia masih sangat mencintai istrinya, yang ternyata istrinya telah pergi meninggalkan Indra sendirian. Aksi nekat inipun adalah bentuk ekspresi Indra kepada istrinya dan kedua anaknya. Indra berharap dampak bunuh dirinya adalah untuk membuat kehidupan kedua anaknya menjadi lebih baik dan istrinya dapat menyesal karena telah meninggalkannya.

Dari kasus ini, aksi gantung diri dan tindakan percobaan bunuh diri memang masih jamak ditemukan di lingkungan masyarakat. World Health Organization (WHO, 2018) melaporkan, secara global setidaknya ada 800 ribu orang tewas akibat bunuh diri setiap tahunnya. Jika dirata-rata, 1 orang mati bunuh diri setiap 40 detik. Lebih lanjut, 78 persen kasus bunuh di seluruh dunia terjadi di negara-negara berkembang. Rata-rata usia yang melakukan aksi bunuh diri berkisar 15 hingga 29 tahun. Tahun 2015, bunuh diri menjadi penyebab kematian ke-17 terbanyak di dunia. WHO, dalam laporan lima tahunannya tentang jumlah rata-rata kematian per 100.000 penduduk menunjukkan, pada tahun 2000, jumlahnya mencapai 3,1 jiwa. Tahun 2005, meningkat tipis menjadi 3,2, di 2010 turun di 3,1, sedangkan pada 2015, menurun lagi menjadi 2,9.

\section{Kasus Bunuh Diri di Indonesia}

Indonesia, sebagai negara dengan jumlah penduduk terbanyak ke-4 di dunia, mengalami naik-turun soal jumlah kematian akibat bunuh diri. Diperkirakan jumlah penduduk Indonesia sebanyak 230 juta jiwa. Setidaknya hampir 3.000 hingga 5.000 jiwa melayang akibat bunuh diri (WHO, 2018).

Wirasto (2012), seorang Psikiater Rumah Sakit Umum Daerah (RSUD) Dr Sardjito Yogyakarta mengungkapkan bahwa penyebab paling umum adanya kasus bunuh diri di Indonesia ialah masalah kesehatan mental, penyalahgunaan alkohol serta obat-obatan terlarang dan masalah keluarga. Selain itu, kesadaran akan adanya depresi juga terbilang rendah.

Wirasto saat diwawancarai oleh penulis pada bulan November 2018 lalu juga menambahkan, bahwa tak semua kasus bunuh diri di masyarakat terdata atau dilaporkan pada aparat setempat. Ia menilai bahwa kematian akibat bunuh diri masih dianggap aib serta memunculkan stigma negatif bagi keluarga yang ditinggalkan. 
Menurut Wirasto pengetahuan dan edukasi kepada masyarakat memegang peran penting dalam menjaga kesehatan mental dan kecenderungan bunuh diri. Karakteristik mereka yang memiliki masalah mental sangat tertutup dan sulit terbuka kepada orang sekitarnya, kerabat, bahkan keluarganya sendiri. Inilah mengapa yang menurutnya menjadi masalah kesehatan mental dan bunuh diri sulit dideteksi secara dini.

Kemudian, Girard (1993) mengungkap motivasi umum mereka yang melakukan bunuh diri. Ia menjelaskan, bahwa faktor yang menyebabkan bunuh diri pada perempuan ialah karena menjadi korban kekerasan dalam rumah tangga (KDRT), tekanan sosial-ekonomi, serta korban kekerasan seksual. Sedangkan pada laki-laki, beban sosial pada budaya patriarki dan tuntutan finansial menjadi faktor terjadinya aksi bunuh diri. Ujung-ujungnya, berbagai tekanan ini mengakibatkan depresi.

Ditambah lagi dengan penelitian yang dilakukan oleh Bertolote dan Fleischmann (2002), menjelaskan, kebanyakan kasus bunuh diri yang terjadi, para pelakunya cenderung tertutup dan tak mau terbuka soal permasalahan depresinya, termasuk kepada kerabat terdekat sekalipun. Selain itu, kegagalan mengendalikan stres dan depresi juga menjadi pendorong seseorang melakukan bunuh diri.

\section{Gunung Kidul dan Mitos Pulung Gantung}

Kabupaten Gunung Kidul terletak di bagian selatan Propinsi Daerah Istimewa Yogyakarta (DIY). Luas kabupaten Gunung Kidul mencapai sepertiga DIY, dan jumlah penduduknya sekitar 750 ribu jiwa, atau 20 persen dari total populasi provinsi yang mencapai 3,59 juta jiwa pada 2016 lalu (Bappeda, 2016). Di Kabupaten yang terkenal dengan keindahan pantainya inilah kasus bunuh diri kerap terjadi.

Menurut hasil wawancara pada 18 November 2018 dengan pengurus LSM Inti Mata Jiwa (Imaji) Jaka Yudistira, Yogyakarta dari tahun 2001 hingga 2016, jumlah kasus bunuh diri di Kabupaten Gunung Kidul ialah 458 kasus. Jika dirata-rata, setiap tahun, ada 33 jiwa yang melayang akibat bunuh diri.

Jumlah kasus bunuh diri tersebut terjadi di 18 kecamatan yang ada di Kabupaten Gunung Kidul. Namun, jika ditilik persebarannya, kasus terbanyak terjadi di Kecamatan Karangmojo, dengan jumlah kasus mencapai 12 kejadian dalam rentang 2015 hingga 2017.

Melihat kelompok usia, lansia dengan rentang umur lebih dari 60 tahun mendominasi jumlah pelaku bunuh diri dengan persentase 39 persen. Peringkat kedua adalah usia produktif dengan umur antara 18 tahun hingga 45 tahun dengan persentase sekitar 34 persen. Jaka menambahkan, sejak Yayasan Imaji berdiri dan mulai menghimpun data sejak 2001, setidaknya ada motivasi yang melatarbelakangi pelaku melakukan aksi bunuh diri.

Untuk pelaku yang berusia lansia, biasanya alasan mereka untuk melakukan bunuh diri adalah kesepian dan sakit menahun. Faktor kesepian ini akibat dari kultur masyarakat Gunung 
Kidul yang memilih merantau ke kota. Akibatnya, para lansia ini sering ditinggalkan sendiri di rumahnya dan menghabiskan waktu dengan tidak melakukan apa-apa di usia senjanya. Kemudian Lansia yang mengalami masalah kesehatan dan tidak kunjung sembuh, biasanya mengalami depresi karena mereka tidak mampu untuk melakukan aktivitas sehari-hari yang biasa dilakukan.

Jaka juga melihat fakta yang menunjukkan pelaku bunuh diri pada usia produktif menunjukkan kenaikan setiap tahun. Menurutnya, pendampingan yang dilakukan yayasannya selama ini juga berfokus kepada mereka yang usia produktif. Ia juga menjelaskan kebanyakan motivasi bunuh diri dari kelompok usia produktif rata-rata karena faktor ekonomi dan permasalahan rumah tangga, ia juga menyayangkan fakta tersebut. Menurutnya kehidupan mereka pada usia produktif masih sangat panjang.

Tetapi ada yang menarik dari kebanyakan kasus bunuh diri di Gunung Kidul. Di Gunung Kidul ada sebuah mitos yang sangat dipercayai masyarakat tentang adanya "Pulung Gantun", dan karena "Pulung Gantung " itulah banyak warga yang dikabarkan memilih mengakhiri hidupnya dengan cara bunuh diri. Darmaningtyas (2002) dalam penelitiannya mengungkapkan bahwa mitos bunuh diri di Gunung Kidul bukan disebabkan oleh Pulung Gantung, melainkan karena adanya tekanan sosial ekonomi. Akibat kekeringan dan ketandusan wilayah tempat tinggalnya, warga Gunung Kidul dilanda keputusasaan yang mendalam dan akut dalam menghadapi sulitnya hidup. Kebudayaan menjadi faktor yang lumrah diperbincangkan untuk menutupi kesalahan dari seseorang. Begitu pula pada mitos Pulung Gantung yang mencoba menutupi alasan pelaku mengakhiri hidupnya. Mulyani dan Eridiana (2018) juga mengungkapkan bahwa dalam suatu kebudayaan, sesuatu yang terulang atau repetisi akan selalu dialami. Begitulah yang terjadi dalam perkembangan cerita mitos Pulung Gantung . Masyarakat terus mengkonsumsi cerita yang disebarkan secara berulang dari satu generasi ke generasi lain, dengan tanpa melihat dan mencari tahu secara langsung kebenarannya. Tanpa disadari cerita mengenai mitos Pulung Gantung tersebut sudah tertanam di dalam benak masyarakat, sehingga memunculkan sebuah persepsi bahwa Pulung Gantung merupakan faktor yang melatarbelakangi seseorang bunuh diri. Kebenaran mengenai mitos Pulung Gantung terbukti setelah terjadi kasus bunuh diri di masyarakat. Seiring berjalannya waktu, istilah pulung sering dikaitkan dengan kasus gantung diri. Sehingga dikenal istilah Pulung Gantung pada masyarakat Gunung Kidul. Menurut cerita yang berkembang, akan ada orang yang gantung diri tepat di mana arah Pulung Gantung itu jatuh. Apabila Pulung Gantung terbang ke arah selatan dan tepat jatuh di salah satu desa di sana, masyarakat meyakini tidak lama akan ada berita yang gantung diri (Mulyani \& Eridiana, 2018).

Laporan BBC yang diterbitkan pada 10 September 2017, makhluk mistis ini sudah dipercayai masyarakat setempat sejak abad ke-16. Wujud Pulung Gantung yang dipercaya oleh 
masyarakat Gunung Kidul berbentuk bola api berpijar, yang konon jika Pulung Gantung tersebut hinggap di sebuah rumah, maka hal tersebut jadi penanda adanya kejadian bunuh diri.

Lebih lanjut, peneliti juga sempat melakukan wawancara pada November 2018 terhadap Barzilla Didik Arifin selaku pendeta pantekosta yang pernah menangani seseorang yang pernah melakukan aksi bunuh diri akibat Pulung Gantung. Barzilla mengungkapkan, orang yang pernah terkena kasus Pulung Gantung mendapat bisikan dari dalam dirinya, bahwa jalan untuk menyelesaikan masalahnya adalah dengan bunuh diri. Dia juga menambahkan biasanya orang yang sudah terkena Pulung Gantung menjadi linglung dan harus mendapatkan perawatan ekstra 24 jam.

Berdasarkan dari paparan latar belakang, peneliti bermaksud untuk meneliti pengalaman dan persepsi tentang Pulung Gantung pada partisipan yang pernah selamat dari upaya bunuh diri serta dari partisipan lain yang terlibat langsung dalam upaya pertolongan. Penelitian ini difokuskan pada pertanyaan sebagai berikut: Apa yang dialami, dipikirkan dan dirasakan oleh partisipan mengenai bunuh diri dan hubungannya tindak percobaan bunuh diri dengan kepercayaan kultural tentang Pulung Gantung?. Manfaat yang dapat diambil dari penelitian ini adalah agar masyarakat memiliki pengetahuan untuk membedakan antara mitos dan realitas Budaya Pulung Gantung yang telah menimbulkan persepsi negatif secara turun temurun. Kemudian, Budaya Pulung Gantung dapat ditangani secara tepat oleh Pemerintah Gunung Kidul untuk mengurangi angka bunuh diri di Gunung Kidul.

\section{Metode Penelitian}

\section{Partisipan}

Penelitian ini menggunakan empat (4) partisipan yang terdiri dari 2 kriteria. kriteria pertama adalah warga Gunung Kidul yang pernah melakukan percobaan bunuh diri akibat pengaruh budaya Pulung Gantung. Partisipan pada kriteria pertama adalah laki-laki berusia 59 tahun dan 63 tahun. Kemudian Partisipan kriteria kedua adalah dua orang warga Gunung Kidul yang masing-masing berumur 42 tahun dan 40 tahun serta sudah lebih dari 25 tahun hidup di Gunung Kidul terkhusus di dusun Karangmojo dan Pendhem dikarenakan kebanyakan kasus bunuh diri sering terjadi di dua dusun tersebut.

\section{Prosedur Pengumpulan Data}

Penelitian ini menggunakan metode penelitian kualitatif dengan pendekatan Etnografi. Secara harfiah penelitian etnografi berarti gambaran sebuah masyarakat, yang meliputi gambaran umum suatu budaya atau kebiasaan, keyakinan, dan perilaku yang berdasarkan atas informasi yang telah dikumpulkan melalui penelitian lapangan (Harris, 2001). Penelitian ini 
berfokus pada analisis psikologi pada perilaku bunuh diri terhadap budaya Pulung Gantung di Gunung Kidul.

Pengumpulan data dilakukan dengan cara wawancara semi terstruktur dan observasi lapangan dengan cara live in. Live in berguna untuk mengobservasi dan mengetahui kebiasaan, keyakinan, dan perilaku partisipan dalam menjalani kehidupannya sehari-hari. Dalam melakukan penelitian, penulis menggunakan alat bantu berupa alat perekam suara untuk proses wawancara, dan buku serta alat tulis untuk catatan lapangan.

Setelah diperoleh hasil rekaman suara berdasarkan wawancara dengan partisipan, selanjutnya hasil rekaman tersebut akan diproses menjadi bentuk verbatim agar penulis dapat melakukan analisis pemaknaan psikologis. Dari hasil pemaknaan psikologis tersebut maka penulis mendapatkan beberapa tema yang kemudian dikelompokan menjadi beberapa kategori. Selanjutnya kategori ini yang menjadi inti dalam pembahasan penelitian. Kemudian hasil dari observasi ini akan dicatat dalam catatan lapangan yang nantinya akan digunakan untuk mendukung beberapa data dari hasil wawancara.

\section{Hasil}

\section{Deskripsi Partisipan 1}

Partisipan 1 adalah warga Gunung Kidul yang bekerja sebagai pencari kayu bakar dan penjual angkringan di daerah Tepus. P memiliki seorang istri dan 3 anak. Laki-laki yang berusia 59 tahun ini awalnya memiliki 4 anak, tetapi anak pertamanya meninggal saat berusia satu minggu setelah dilahirkan.

Di keluarga hanya P1 yang bekerja dan menghidupi seluruh kebutuhan keluarga. Pekerjaan P1 adalah pencari kayu, tetapi sebagai pencari kayu P1 tidak melakukan pekerjaannya setiap hari, mengingat kondisi P1 yang sudah mulai tua dan sudah tidak kuat untuk melakukan pekerjaan berat. Maka dari itu untuk menopang ekonomi keluarganya ketika malam P memutuskan untuk berjualan angkringan yang dibantu oleh istrinya. Modal awal untuk berjualan angkringan didapat P1 dengan cara meminjam uang kepada Bank plecit sebesar 500 ribu. Kemudian, setelah usaha angkringannya berjalan ternyata P1 tidak mampu untuk mengembalikan cicilan uang yang dipinjam. Akibatnya, hal tersebut membuat P1 terbebani dan memiliki banyak pikiran dari masalah hutangnya. P1 juga bercerita bahwa ia tidak ingin masalah yang dihadapinya ini diketahui oleh keluarganya.

Dari proses wawancara P1 mengaku sebagai kepala keluarga ia adalah orang yang keras dan memegang prinsip bahwa semua masalah dalam keluarga hanya P1 yang boleh tahu. Menurutnya kepala keluarga adalah orang yang dapat menyelesaikan masalah keluarga dan 
meringankan beban keluarganya. Tetapi, dari prinsip hidup yang dianutnya P1 mengaku itu membuatnya terbebani dan merupakan awal P1 melakukan percobaan bunuh diri.

\section{Deskripsi Partisipan 2}

Partisipan kedua adalah laki-laki yang berusia 64 tahun. ia adalah salah satu seorang warga Gunung Kidul yang pernah melakukan percobaan bunuh diri dengan cara gantung diri. Ia bekerja sebagai petani yang sehari-hari berada di ladang untuk menggarap lahan milik orang lain di daerah tepus, Gunung Kidul. P2 memiliki seorang istri dan 2 orang anak. Tetapi saat ini P2 di rumah hanya hidup bersama istrinya saja.

Awal terjadinya masalah menurut P2 adalah ketika ia tidak mampu untuk berjalan atau mengalami kelumpuhan akibat sakit gula yang dideritanya. Dari hasil wawancara penyakit gulanya tersebut terjadi dengan cukup aneh. Pasalnya, menurut P2 makanan yang ia konsumsi untuk makanan sehari-hari hanyalah olahan sayur-sayuran seperti daun singkong, dan mete. Tetapi, ketika memeriksakan ke dokter hanya dalam tempo satu minggu gula darah yang terkandung dalam tubuhnya mencapai angka $400 \mathrm{mg} / \mathrm{dl}$.

Tidak hanya sampai disitu, menurutnya karena penyakit yang dideritanya tidak kunjung sembuh dan sudah beberapa kali mencoba untuk berobat ke dokter, tetapi hasilnya sama saja menambah pikiran P2. P2 yang saat itu hanya bisa berbaring di tempat tidur membuat segala urusan yang selama ini harus ditanggungnya dikerjakan oleh istrinya.

P2 juga menjelaskan bahwa sebenarnya yang paling membuat P2 kesusahan adalah ketika dia harus dibantu untuk mengeluarkan kotorannya dengan sendok selama 6 bulan. Kondisi inilah yang memicu P2 untuk melakukan percobaan bunuh diri setelah mengaku diajak oleh suara yang tidak dikenalnya.

Dari paparan di atas untuk memahami kondisi dari P1 dan P2 lebih jauh, peneliti memulai dengan analisis verbatim yang kemudian berlanjut dengan tahap pemaknaan psikologis. Setelah proses pemaknaan psikologis selesai, penulis membuat kategori besar dari data yang didapatkan, selanjutnya penulis mencoba menuliskan hal-hal yang dirasakan dan dialami oleh partisipan melalui peristiwa yang telah ia alami. Berikut adalah penjelasan dari temuan peneliti:

\section{Awal Munculnya Masalah}

P1 menceritakan bahwa penyebab dirinya melakukan percobaan bunuh diri adalah ketika dia mengalami banyak masalah dan membuatnya terbebani. Salah satu yang menyebabkannya adalah ketika P1 meminjam uang kepada bank plecit untuk modal membuka angkringan. 
WACANA

"Keadaan saya susah. La sampai sekarang ini saya bikin warung ini tidak bisa melunasi hutang. Ngulur-ngulur terus susah mas. Terus ketambahan apa-apa itu. Jadi anak-anak mau gimana ya udah seperti itu. Jadinya ya susah mas"

Keadaan tersebut disadari P1 karena ia selalu menunda-nunda untuk membayar cicilan hutang guna memenuhi kebutuhan hidup sehari-harinya. Selain itu, P1 juga beranggapan masalah yang memicunya untuk melakukan percobaan bunuh diri disebabkan ia tidak menceritakan masalah yang dihadapinya kepada keluarga.

"aku itu tidak apa-apa..kalau ada masalah ya hanya saya yang ngatasi..jadi mau cerita sama anak ya gimana..keadaanya juga sama susahnya..kan akhirnya yang susah saya sendiri..jadi ya saya sendiri yang susah..la ini kan bingung tidak bisa cerita kemana-mana..kan akhirnya ini ruwet pikirannya..isinya hanya susah"

Menurut P1 sebagai kepala keluarga dia merasa tidak pantas untuk menceritakan masalahnya kepada anaknya. Karena menurut P1, anaknya juga sedang dalam keadaan susah. Oleh karena itu, P1 memilih untuk menyimpan masalahnya itu sendiri.

Sedangkan bagi P2, pemicu dirinya melakukan percobaan bunuh diri adalah penyakitnya yang tak kunjung sembuh.

"Iya saya mikir aku sakit kok tidak sembuh-sembuh..lagi kalau mandi pun ya dituntun..pakai celana ya dipakaikan"

Akibat dari penyakitnya tersebut, P2 menceritakan bahwa untuk memakai celana ia harus dibantu oleh istrinya. Kondisi tersebut menurut P2 membuat pikirannya terbebani. Lebih lanjut, P2 juga menjelaskan yang paling membuatnya terbebani adalah masalah buang air besarnya.

“itu..yang paling tak susahi itu kalau mau buang air besar..itu yang paling saya susahi..itu tidak bisa keluar..kering kotoran itu..saya itu di kamar mandi menghadap pintu mas..nanti jam dua belas itu udah kerasa la nanti bisa keluar itu jam tiga..itu tidak bisa keluar mas kering itu..saya itu tidak malu mas..jan itu yang paling saya susahi mas..”

P2 menjelaskan akibat dari kondisi kesulitan buang besarnya ini sampai membuat kotorannya menjadi kering sehingga susah untuk dikeluarkan. Sehingga menurut P2, ia baru bisa mengeluarkan kotorannya setelah tiga jam lamanya. 
WACANA

P2, sebenarnya sudah menempuh jalur medis untuk memeriksakan sakitnya tersebut. Ia juga menceritakan bahwa jalur medis sama sekali tidak menyembuhkan penyakit yang dideritanya.

"sudah berobat kemana-mana...ada kalau 8 dokter..orang pintar iya juga..kalau kata orang pintar sini itu seperti ini..yang sana seperti ini..pokoknya tidak ada yang sama..la terus saya diantar ke orang pintar daerah jaten..katanya rumah saya tiangnya belum genap..la setelah itu saya mbangun rumah habis 8juta..lelakon apasaja sudah saya lakukan..semut yang dari jepang itu juga katanya bisa.tetapi ya tidak sembuh..

Dari pernyataan tersebut, P2 menjelaskan bahwa ia sudah mengunjungi delapan dokter agar penyakit yang dideritanya dapat disembuhkan. Kemudian karena dokter tidak mampu menyembuhkan penyakitnya, P2 mencoba pengobatan alternatif dengan cara meminta bantuan orang pintar atau dukun untuk kesembuhan penyakitnya. P2 mengaku sudah menjalankan semua perintah yang diberikan oleh orang pintar yang ia datangi, seperti membangun rumahnya karena tiang di rumahnya belum genap. Tetapi setelah mengikuti semua anjuran tersebut penyakit P2 tidak lekas membaik juga.

P2 juga mengungkapkan bahwa dirinya sempat dibuat bingung oleh kesembuhan penyakitnya. Hal itu disebabkan karena penyakitnya dapat sembuh hanya dengan meminum daun sirsak yang banyak ditemui di sekitar tempat tinggalnya serta tidak memerlukan biaya besar untuk mendapatkannya "tapi yang membuat saya bingung itu sembuhnya kok hanya pakai daun sirsat..tidak membutuhkan biaya..dan dimana-mana ada..

\section{Mimpi /Ajakan Bunuh Diri}

Pada P1 saat dalam keadaan susah ia mengaku didatangi anak pertamanya yang sudah meninggal di dalam mimpi. Kemudian dia menjelaskan ajakan anaknya tersebut adalah untuk menyelesaikan masalahnya.

"ya, ayo ikut-ikut..melambaikan tangan terus, mengajak terus. Tapi saya itu berhenti juga.tapi saya sempat kehilangan jejak dengan yang ngajak saya itu..saya berhenti.. saya berhenti anak saya itu melambaikan tangan mengajak lagi..dan itu di gunung..coro aku mlayu raiso..tapi perasaanku waktu itu..aku tidak menabrak batu..enak aja jalannya..tapi aslinya jalannya tidak bisa dilalui sebenarnya..la setelah itu saya itu sama anak saya diajari nali-nali pakai akar pohon..la saya sampai tempat tujuannya itu..dia bilang cara menyelesaikan masalah ya hanya dengan cara seperti ini" 
WACANA

P1 menjelaskan saat mengikuti ajakan anaknya, ia merasa tidak ada beban saat melewati jalan berbatu yang sulit untuk dilalui. P1 juga menambahkan tiap kali P1 menghentikan langkah, anaknya selalu melambaikan tangan untuk terus mengajaknya menyelesaikan masalah dengan cara gantung diri.

Pada kasus pertama, kedatangan anak dialami P1 dalam mimpi, sedangkan pada kasus kedua ini, P2 mengaku mendengar bisikan berupa ajakan untuk mengajaknya melakukan percobaan bunuh diri.

"bukan mimpi itu..ada wujudnya..bukan mimpi..sudah ayo ikut aku sebentar saja..sudah ayo sebentar..ya seperti itu ngajaknya.. la di kamar mandi itu ada tali dadung.itu saya talikan..sett..la terus itu saya pakaikan di leher..tapi sebenarnya kaki saya waktu itu masih menyentuh tanah.

P2 mengaku mendengar bisikan pada saat dirinya sedang istirahat di dalam kamar. P2 juga menjelaskan saat mengikuti bisikan tersebut ia diarahkan menuju kamar mandi untuk mengambil tali yang digunakan untuk melakukan gantung diri.

\section{Hilangnya Kesadaran}

Setelah mengalami mimpi yang berisi ajakan untuk melakukan bunuh diri, Partisipan kehilangan kesadaran. Hilangnya kesadaran ini terjadi sesaat sebelum Partisipan melakukan upaya bunuh diri. Pada P1 hilangnya kesadaran dimulai ketika ia didatangi anaknya ketika hendak tidur. P1 mengaku awalnya tidak senang dengan kehadiran anaknya dan berusaha untuk mengusirnya.

"la itu ndatangi saya ketika saya mau tidur..la itu pengenku ya tak suruh pergi..tapi akhirnya ya aku ikut juga..tapi ikut itu yang ngajak ya wujud anak saya..jalannya juga cepet dan kencang..ya setau saya itu anak saya..makanya saya ikutin..jadinya ya tidak sadar soalnya setau saya itu anak"

P1 menceritakan bahwa akhirnya ia mengikuti ajakan anaknya untuk melakukan gantung diri. P1 menambahkan alasan mengikuti ajakan tersebut karena yang mengajaknya untuk melakukan upaya bunuh diri adalah anaknya, kemudian saat mengikuti ajakan tersebut ia dalam keadaan tidak sadar. P1 juga merasa saat berjalan keluar rumah ia langsung kehilangan kesadarannya. P1 bercerita bahwa saat ia berjalan untuk mengikuti ajakan anaknya ia tidak merasakan apapun dan beranggapan bahwa rasanya seperti mimpi.

"Lha saya itu dari rumah ya jalan terus mas..tidak sadar kalau ternyata itu mimpi.. la itu saya dari rumah ya terus..tidak sadar saya itu..keluar dari rumah itu langsung tidak sadar. ya rasanya mimpi..tidak merasakan apapun.." 
Lebih lanjut P1 menjelaskan bahwa ia masih dalam keadaan tidak sadar ketika diturunkan dari proses gantung dirinya.

"ya saya setelah diturunkan itu masih belum sadar saya itu.tapi sekitaran setengah jam satu jam sebelumnya ya sudah nggantung..tapi kenyataanya tibatiba saya di rumah..sudah dibopong orang banyak.."

P1 menjelaskan bahwa dirinya tidak menyangka bahwa ia telah melakukan gantung diri. P1 juga merasa dirinya tiba-tiba sudah berada di rumah dan banyak orang yang membopongnya setelah proses gantung dirinya.

Pada P2, proses hilangnya kesadaran terjadi ketika ia mendengar bisikan saat beristirahat di dalam kamarnya. P2 mengaku tiba-tiba ia mendengar suara bisikan yang tidak dikenalnya.

"nganu..waktu tiduran itu..terus oya-ayo ikut aku sebentar saja..la ya maaf ya..tiba-tiba ikut saja..terus saya itu jalan mengikuti.mengikuti tanpa bertanya kenapa mau ikut..la itu di kamar mandi..ada senar.terus saya talikan ke leher..

P2 menjelaskan dirinya dalam keadaan tidak sadar saat mengikuti bisikan yang mengajaknya untuk melakukan gantung diri tersebut. P2 mengaku saat mendengar bisikan tersebut secara tiba-tiba ia mengikutinya. Bisikan tersebut kemudian mengarahkan P2 menuju kamar mandi untuk mengambil senar dan melakukan gantung diri.

Kemudian P2 juga menceritakan bahwa ketika dirinya melakukan gantung diri ia dalam keadaan tidak sadar.

"la waktu gantung diri itu langsung pleng mas..pleng tidak ingat..la itu aku baru sadar itu setelah diturunkan sama tetangga saya itu..wo wo sadar wo..kamu itu sadar tidak habis melakukan apa..jane kaki saya masih napak tanah mas.."

Berbeda dengan P1 yang belum sadar ketika diturunkan, pada P2 kesadaran mulai kembali muncul ketika ia diturunkan dari gantung dirinya. P2 juga menceritakan bahwa masyarakat sekitar berusaha menyadarkan dirinya usai melakukan gantung diri

\section{Kehidupan Sesudah Kegagalan Bunuh Diri}

Pasca upaya percobaan bunuh dirinya dan kesadaran Partisipan pulih seperti sedia kala, ada beberapa perubahan yang terjadi didalam kehidupan Partisipan. Pada P1, ia mengaku merasa terbebas dan lega karena ia merasa menjadi lebih dekat dengan keluarganya. 
WACANA

“.Saya itu, sekarang itu sudah tidak apa-apa saya itu..sudah enak..sekarang ini lo..tapi enak tapi nanti kalau pikiran saya agak nganu ya..saya itu orangnya keras mas..tapi keluarga bisa ngemong saya kalau lagi banyak pikiran ya sekarang diapiki sama mereka..keluarga saya itu..kalau lagi seperti itu..biasanya nanti akan seperti itu lagi..jadi keluarga saya ya berusaha menenangkan saya mas kalau lagi ada masalah.."

P1 mengaku keluarganya lebih bisa mengerti dirinya setelah upaya bunuh dirinya gagal. Ia juga merasa dibuat tenang hatinya oleh keluarga ketika mempunyai masalah, sehingga keluarga jadi lebih tahu ketika P1 sedang terbebani pikirannya. Selain itu, P1 juga bercerita bahwa untuk menenangkan pikirannya ia memilih untuk menyibukkan diri.

“jadi tidak ada pikiran macem-macem ya saya jadi tenang..tapi sampai sekarang bisa tenang gara-gara ada kegiatan ini mas..kan dulu berhenti jualan itu tidak ada tujuan mau jualan lagi saya.."

P1 mengungkapkan bahwa sebelumnya ia tidak ada niat untuk membuka kembali angkringannya yang telah ditutup karena masalah yang menyebabkannya melakukan upaya bunuh diri. Tetapi P1 mengurungkan niatnya tersebut karena dengan dirinya memiliki aktivitas ia dapat lupa dengan masalah yang telah menimpanya.

Pada P2 pasca melakukan percobaan bunuh diri, ia mengungkapkan bahwa dirinya menjadi orang yang sehat.

"baik-baik aja mas..seperti tidak ada apa-apa..seperti orang yang sehat gitu mas.."

Lebih lanjut, P2 juga merasa bersyukur karena ia dapat melanjutkan aktivitasnya kembali sebagai petani.

“.ya seneng mas..seneng..saya itu hanya duduk ingin pergi ke ladang..kalau kata orang sana ke sawah..sekarang sudah seneng saya..kalau mau pergi ya pelanpelan.."

"ya seneng mas..saya itu tidak bisa jalan 2 tahun..sekarang sudah bisa ke ladang..mencangkul..ngasih pupuk.."

P2 juga menjelaskan bahwa ketika ia mengalami sakit gula dan mengalami kelumpuhan yang ada di dalam pikirannya hanyalah pergi ke ladang untuk bertani. Ia mengaku setelah kejadian bunuh diri, kemudian menjadi lebih sehat, ia bisa pergi ke ladang untuk bertani kembali. 


\section{Pulung Gantung dan Perilaku Bunuh diri}

Walau sebagai anggota masyarakat yang lahir dan besar di wilayah Gunung Kidul, Partisipan memahami makna Pulung Gantung. Namun di dalam kasus dirinya yang pernah sampai pada taraf akan mengakhiri hidupnya, Partisipan secara retrospektif mengakui bahwa tindakan percobaan bunuh dirinya tidak berkaitan dengan Pulung Gantung. P1 menjelaskan bahwa yang menyebabkan dirinya melakukan upaya bunuh diri bukanlah Pulung Gantung. Tetapi, karena masalah yang dihadapinya serta ajakan dari anak pertamanya yang telah tiada.

"ya saya itu tidak apa-apa mas..tapi kalau waktu keadaan seneng ya saya seneng. La waktu keadaan susah itu kan panas mas hatinya..tapi saya sendiri ya sudah susah, banyak kebutuhan, sok sering-sering itu sok dingertiin gitu lo..dulu itu..tapi kalau langsung banyak pikiran ya kejadian nggantung itu..banyak pikiran itu..tapi itu yang berbuat anak saya yang mbawa itu..la saya itu ngetutke..kemana-mana ngetutke..dibawa."

Dari pernyataan di atas, P1 menjelaskan bahwa penyebab dirinya melakukan upaya bunuh diri adalah karena masalah finansial yang dihadapi. Kemudian, saat masalah finansial tersebut membuatnya merasa terbebani anak pertamanya yang sudah meninggal mendatanginya dalam mimpi dan mengajaknya untuk menyelesaikan masalah dengan cara gantung diri.

P1 menambahkan bahwa sebenarnya dia percaya bahwa Pulung Gantung itu ada. kemudian P1 mengaku setelah peristiwa bunuh dirinya ia menjadi takut ketika mendengar Pulung Gantung.

"ya itu ada mas..setelah kejadian saya itu tadi ada orang yang bilang Pulung Gantung itu hati saya jadi takut mas..nyinggung itu lir-lir hati saya..saya takut mas..la itu kalau ada saya tetap di dalam rumah..mumpet"

P1 menceritakan ketika Pulung Gantung datang ia merasa takut dan memilih untuk tinggal di rumah dan bersembunyi di dalam.

Pada kasus P2, ia mengungkapkan bahwa tidak mempercayai bahwa penyakit lumpuh yang menyebabkan dirinya mendapat bisikan untuk melakukan percobaan bunuh diri tersebut disebabkan oleh santet ataupun Pulung Gantung.

"oh..kalau santet (Pulung Gantung) itu saya percaya ada mas.tapi kalau saya disantet ya tidak percaya mas..la karena tidak percayanya itu ya karena tadi kejawi saya itu ngapusi orang..kaya..tapi hutang gak bayar marah-marah..la disantet orang saya percaya..la coba saya..ya tidak percaya..saya percaya kalau santet (Pulung Gantung) itu ada..tapi kalau disantet tidak percaya saya mas..” 
P2 juga mengungkapkan, bahwa ia mempercayai bahwa Pulung Gantung atau santet itu ada, tetapi P2 tidak mempercayai penyebab penyakitnya yang berujung pada percobaan bunuh dirinya disebabkan oleh santet ataupun Pulung Gantung. P2 menambahkan bahwa selama ini dirinya selalu berbuat baik kepada semua orang, dan oleh karenanya dia tidak mempercayai ada orang yang tega melakukan hal buruk terhadap diri nya.

\section{Diskusi}

Bunuh diri secara terminologi adalah tindakan yang disengaja dengan maksud untuk mengakhiri hidup dirinya sendiri (Nock, dkk., 2008). Perilaku bunuh diri secara spesifik digolongkan ke dalam 3 bentuk kategori, yang pertama adalah Suicide ideation, yaitu pikiranpikiran yang mengacu pada keinginan untuk mengakhiri hidup; suicide plan, yang mengacu pada cara-cara atau metode khusus untuk mengakhiri hidup; dan suicide attempt yaitu usaha yang secara langsung dilakukan dan berpotensi melukai diri sendiri dengan tujuan untuk mengakhiri hidup (Borges, dkk., 2008).

Peristiwa bunuh diri merenggut nyawa 800.000 orang setiap tahunnya di seluruh Dunia. Peristiwa ini tidak hanya ditemukan pada negara yang memiliki tingkat pendapatan yang tinggi atau negara maju, tetapi juga terjadi di seluruh Dunia, bahkan sebanyak 79\% terjadi pada negara negara berkembang yang didominasi oleh kelas sosial menengah dan menengah kebawah (WHO, 2019). Data yang dihimpun WHO (2019) mengungkapkan bahwa sebanyak $20 \%$ peristiwa bunuh diri dilakukan dengan cara meminum racun, menggunakan senjata api, dan sebagian besar yang terjadi di daerah pertanian, pedesaan, dan negara-negara dengan negara berpenghasilan rendah adalah dengan cara menggantung diri.

Individu yang beresiko mengalami percobaan bunuh diri merupakan individu yang sedang berada dalam momen krisis kehidupan, ketidakmampuan mengatasi stress, persoalan ekonomi, kegagalan dalam menjalin hubungan, penyakit menahun (WHO, 2019). Sebagai tambahan pengalaman berkonflik, bencana alam, kekerasan, abuse, kehilangan, dan perasaan terisolasi berkaitan erat dengan perilaku bunuh diri. Senada dengan pernyataan yang dikemukakan oleh WHO, British Columbia Ministry of Health and Centre for Applied Research (2007) mengemukakan bahwa faktor situasional seperti konflik interpersonal, pengalaman dipermalukan atau kehilangan, dan faktor stressor kehidupan (stressful life events) seperti masalah keuangan, masalah hukum, masalah kesehatan atau kehilangan pekerjaan meningkatkan resiko bunuh diri pada individu. Sementara penelitian yang dilakukan oleh Tang 
dan Crane (2006); Hooley, Franklin, dan Nock (2014) menghasilkan temuan bahwa penyakit kronis memicu ide-ide munculnya perilaku bunuh diri pada individu.

Pada P1 yang memicu dirinya melakukan upaya bunuh diri adalah masalah hutang yang tidak bisa ia selesaikan. Persoalan hutang tersebut sangat membebani P1 ditambah ia memilih untuk tidak menceritakan masalahnya terhadap keluarga. Salah satu model teoritik yang dapat digunakan untuk mengurai peristiwa tersebut adalah model integrated motivational-volitional model (O'Connor \& Nock, 2014). Model ini menjelaskan bahwa perilaku bunuh diri akan terjadi dalam tiga tahap, pertama pre-motivational phase yang merupakan faktor yang memicu bunuh diri, kedua motivational phase yang merupakan ide dan intensi untuk bunuh diri, dan yang terakhir volitional phase atau keputusan bunuh diri. Melalui model tersebut terlihat bahwa P1 merasa kalah dan malu oleh masalah hutang yang tidak bisa diselesaikannya (Pre-motivational phase), kondisi ini kemudian mendorong P1 kepada tahap motivational phase yang muncul dalam bentuk ide atau intensi bunuh diri. O'Connor dan Nock (2014), juga menjelaskan bahwa ketika individu merasa terjebak dalam masalahnya ia akan cenderung memunculkan ide-ide bunuh diri dan semakin meningkat ketika individu tersebut tidak mendapatkan dukungan sosial. Pernyataan tersebut didukung oleh penelitian yang dilakukan oleh Centers for Disease Control (2015) yang menghasilkan temuan bahwa individu yang beresiko melakukan bunuh diri menunjukkan keengganan untuk mencari bantuan di tengah kesulitan yang dihadapi sehingga mengakibatkan ia tidak mendapat dukungan sosial yang dibutuhkannya.

Sementara pada P2 yang memicu dirinya melakukan upaya bunuh diri adalah masalah penyakit lumpuhnya yang tak kunjung sembuh, dan mengakibatkan dirinya tidak bisa melakukan pekerjaanya sebagai petani. Selain kelumpuhan, P2 juga menderita gangguan fungsi pencernaan yang mengakibatkan ia tidak dapat membuang fesesnya secara normal dan harus dibantu oleh istrinya menggunakan sendok untuk mengeluarkannya. Hal ini selaras dengan data yang diperoleh WHO (2019) yang mengatakan bahwa penyakit kronis yang menahun dapat menjadi faktor penyebab perilaku bunuh diri. Sama halnya dengan penelitian yang dilakukan oleh American Foundation for Suicide Prevention (2015). Penelitian tersebut menjelaskan bahwa masalah kesehatan fisik kronis yang memunculkan rasa sakit yang tak tertahankan kemudian memunculkan ketergantungan terhadap orang lain dan akhirnya merasa menjadi beban bagi orang lain dalam rentang waktu yang lama mengakibatkan perilaku bunuh diri.

Proses terjadinya upaya bunuh diri pada P1 ditandai dengan beberapa peristiwa yang mendahului. Seperti, P1 yang bermimpi didatangi oleh anak pertamanya yang sudah meninggal untuk diajak menyelesaikan masalah. Mimpi ini terjadi selama kurun waktu satu minggu dan terjadi berulang kali. Mimpi banyak dikaitkan dengan peristiwa bunuh diri, umumnya terjadi 
pada individu yang memiliki faktor risiko. Hal ini jelas pada hasil penelitian yang dilakukan oleh Ohayon, dkk., (1997) yang menerangkan bahwa ada hubungan yang kuat pada munculnya mimpi yang berulang dengan pola yang sama dan kecenderungan gangguan kecemasan serta gangguan depresi.

Dalam APA Dictionary of Psychology (2020) mimpi didefinisikan sebagai keadaan sadar fisiologis dan psikologis yang terjadi selama tidur dan sering ditandai dengan beragam sensorik endogen, motorik, emosi, dan pengalaman lainnya. Mimpi yang sering terjadi pada orang dewasa dianggap sebagai indikasi psikopatologi umum. Menurut Rims dan Pietrowsky (2019) konten dari mimpi mengindikasikan kondisi kesehatan mental, pengalaman afeksi, emosional dan mood dalam kehidupan sehari-hari individu. Lebih lanjut mereka mengungkapkan Salah satu psikopatologi yang direfleksikan melalui mimpi adalah kecemasan (Rims \& Pietrowsky, 2019). Hal ini selaras dengan Pengalaman P1 yang mengaku merasa sangat terbebani dan menjadi cemas karena tidak dapat menyelesaikan permasalahan hutang yang dihadapinya. Ketidakmampuan ini menggambarkan bentuk maladaptif dalam diri P1. Peristiwa yang dialami oleh P1 kemudian menjadi pemicu munculnya indikasi kecemasan yang direfleksikan dalam mimpi saat bertemu anaknya.

Temuan dari Coryell, dkk., (1986) menggambarkan frekuensi kecenderungan bunuh diri pada individu dengan gangguan kecemasan cukup tinggi. Hal ini didukung oleh hasil penelitian dari Choi, dkk., (2011) yang menemukan bahwa gejala kecemasan adalah faktor risiko independen terhadap ide bunuh diri. Dengan demikian, gejala kecemasan dapat digunakan untuk pemeriksaan awal pada individu dengan kecenderungan bunuh diri. Sama halnya dengan penelitian yang dilakukan oleh Nepon, dkk., (2010) yang menemukan bahwa $70 \%$ individu yang melakukan usaha bunuh diri mengalami gangguan kecemasan. Temuan tersebut selaras dengan kondisi P1 yang mengalami kecemasan akibat masalah hutang dan tidak menceritakan masalahnya terhadap keluarga. Kecemasan tersebut termanifestasikan melalui mimpi bertemu dengan anaknya.

Berbeda dengan P1, P2 tidak mengalami mimpi namun ia mendengar suara yang memberi ajakan untuk bunuh diri. Peristiwa tersebut terjadi kala P2 dalam keadaan setengah sadar ketika ia sedang beristirahat. Pada berbagai waktu, dan dalam berbagai keadaan, suara telah dipandang sebagai fenomena religius atau spiritual (suara dewa, setan, malaikat), pengalaman supranatural atau psikis (indikasi hantu atau telepati), pengalaman psikologis (pasca-trauma, disosiatif, psikotik), atau sepenuhnya normal (suara hati, pikiran sendiri, inspirasi kreatif, pengalaman duka, pengalaman hipnopompik; halusinasi yang terjadi ketika bangun, dan hipnagogik; halusinasi yang terjadi ketika tidur). Suara yang didengarkan oleh P2 
dimaknai sebagai 'bisikan' atau 'ajakan' dan hal ini mengindikasikan adanya kecenderungan halusinasi auditorik.

Halusinasi auditorik adalah persepsi suara yang salah dan telah digambarkan sebagai pengalaman kata-kata internal atau suara-suara yang tidak memiliki asal nyata di dunia luar dan dianggap terpisah dari proses mental seseorang (Psychiatrist, 2010). Banyak penelitian yang menjelaskan bahwa munculnya halusinasi auditorik berkaitan erat dengan adanya gangguan depresi, stress dan penyakit fisik yang kronis (Souminen, K, dkk., 2004). Hasil penelitian yang dilakukan oleh Fujita, dkk., (2015) mengungkapkan bahwa halusinasi verbal auditoris dapat meningkatkan resiko upaya bunuh diri pada individu yang memiliki ide-ide bunuh diri.

Sementara itu, menurut penelitian yang dilakukan oleh American Foundation for Suicide Prevention (2015) salah satu pemicu seseorang melakukan upaya bunuh diri adalah adanya permasalahan gangguan psikologis seperti, Stressful Life Events, dan Serious or Chronic Physical Health Problems,. Hal ini selaras dengan kondisi P2, khususnya pada faktor Serious or Chronic Physical Health Problems. P2 mengalami kelumpuhan dalam waktu yang sangat lama. Kondisi fisik P2 ini juga menjadi penyebab dari munculnya perasaan terbebani yang dialami oleh P2.

Lebih lanjut, pada kasus P2 akibat dari penyakit fisiknya tersebut ia tidak mampu melakukan kegiatannya sebagai petani dan menyerahkan segala urusan keluarga kepada istrinya. Kondisi ini juga dirasakan oleh P2 sebagai salah satu yang memicu dirinya melakukan upaya bunuh diri. Hal ini juga didukung oleh pernyataan dari O'Connor dan Nock (2014) bahwa perasaan menjadi beban bagi orang lain (burdensomeness) merupakan prediktor independen dari munculnya ide bunuh diri pada berbagai kelompok individu termasuk di antaranya lansia dan individu dengan penyakit kronis.

Temuan lain yang ditemukan penulis pada penelitian ini adalah hilangnya kesadaran pada P1dan P2 sesaat sebelum upaya bunuh diri dilakukan. Pada P1 setelah bermimpi bertemu dengan anaknya, ia merasa kehilangan kesadaran dan baru kembali sadar saat digotong oleh masyarakat sekitar. Sementara pada P2 proses hilangnya kesadaran dimulai ketika ia mendengar bisikan untuk mengajaknya melakukan upaya bunuh diri dan kembali sadar pada saat diturunkan oleh masyarakat sekitar.

Kehilangan kesadaran yang dialami oleh kedua partisipan ini mengindikasikan adanya gangguan disosiatif trance and possession. Berdasarkan penggolongan disosiatif pada DSM V, dissociative trance masuk dalam kategori Unspecified Dissociative Disorder. Gangguan disosiatif itu sendiri dipahami sebagai gangguan yang terjadi dalam kesadaran, ingatan, identitas, emosi, persepsi, representasi tubuh, kontrol motorik, dan perilaku (APA, 2013). Kondisi ini berpotensi mengganggu setiap area fungsi psikologis, dan banyak ditemukan pada individu yang 
sebelumnya mengalami trauma termasuk diantaranya rasa malu yang tak tertahankan dan kebingungan untuk menyembunyikan keadaanya.

Pada dissociative trance individu akan mengalami hilangnya kesadaran menyeluruh yang disertai dengan keterlambatan respon atau menurunnya kepekaan terhadap rangsangan lingkungan. Keterlambatan respon ini dapat disertai dengan gerakan di luar kendali yang tidak disadari (APA, 2013). Hal ini selaras dengan hasil penelitian yang dilakukan oleh Ozturk dan Sar (2008) yang menghasilkan temuan bahwa individu yang terdiagnosis dengan gangguan disosiatif memiliki tingkat suicidal ideas yang tergolong tinggi. Sama halnya penelitian yang dilakukan oleh Foote, dkk., (2008) yang mengungkapkan bahwa gangguan disosiatif sangat berkaitan erat dengan munculnya self harm dan suicidality.

Setelah upaya bunuh diri pada P1 dan P2, mereka terlihat mengalami beberapa perubahan dalam hidupnya. P1 yang sebelumnya adalah orang yang tertutup kepada keluarganya kini ia menjadi individu yang lebih terbuka kepada orang-orang di sekitarnya. Hal ini juga membantu P1 memperoleh dukungan keluarga sehingga membantunya untuk kembali bekerja untuk mencukupi kebutuhan keluarga. Sama halnya dengan penelitian yang dilakukan oleh Zhai, dkk., (2015) yang mengungkapkan bahwa lingkungan keluarga sangat berkaitan erat dengan faktor resiko suicidal ideation. Hasil penelitian tersebut juga menemukan bahwa lingkungan keluarga dapat menjadi prediktor dan pencegahan perilaku bunuh diri pada individu. Hal ini selaras dengan pengalaman P1 yang menjadi lebih bisa mengatasi masalah yang dihadapinya dan memiliki emosi yang lebih stabil karena bisa membagi beban dengan bercerita kepada keluarga. Pertanyaan ini didukung oleh penelitian Reider dan Sims (2016) yang menemukan bahwa salah satu penanganan dan pencegahan yang efektif dalam menangani individu dengan suicide ideation adalah dengan menggunakan family base preventive interventions. Lebih lanjut relevansi dari ikatan keluarga dan individu menjadi lebih kuat khususnya pada masa-masa krisis. Saat individu mengalami masa krisis arti keluarga berubah menjadi lebih penting dan dibutuhkan, sehingga dengan sendirinya jika individu memiliki ikatan keluarga yang erat dapat mengurangi resiko bunuh diri (Fitzgerald, dkk., 2010).

Sementara pada P2 pasca upaya bunuh diri ia secara tiba-tiba sembuh dari kelumpuhannya dan menjadi lebih sehat. Kondisi ini membuat P2 kembali bisa beraktivitas sebagai petani yang tidak bisa ia lakukan ketika sakit. Setelah kembali ke ladang P2 sering melakukan aktivitas fisik seperti berjalan kaki menuju ladang, mencangkul, dan bercocok tanam. Hingga sekarang aktivitas fisik yang dilakukan oleh P2 membantunya untuk menjadi lebih sehat dan menjauhkan P2 dari pikiran-pikiran untuk bunuh diri. Senada dengan hal tersebut Ghose, dkk., (2018) menghasilkan temuan bahwa keterlibatan dalam aktivitas fisik dapat membantu lansia dalam menurunkan pikiran bunuh diri dan upaya-upaya bunuh diri. Lebih lanjut Sun, dkk., (2013) mengungkapkan bahwa di atas 90\% lansia di China yang berjalan 
kaki atau bersepeda selama 10 menit setiap hari menunjukkan penurunan signifikan terkait ideide bunuh diri.

Melihat dari paparan di atas, tingginya angka bunuh diri di Gunung Kidul yang sering dikaitkan dengan fenomena Pulung Gantung, terbantahkan oleh pernyataan P1 dan P2 yang mengatakan pengalaman bunuh dirinya bukan disebabkan oleh Pulung Gantung . Meski P1 dan P2 menyangkal tindakan bunuh dirinya diakibatkan oleh Pulung Gantung, tetapi mereka mempercayai bahwa Pulung Gantung itu benar adanya. Kepercayaan terhadap Pulung Gantung pada masyarakat Gunung Kidul yang telah ada sejak dari leluhur mereka menjadi gagasan primordial yang diturunkan lintas generasi. Gagasan primordial inilah yang disebut oleh Jung (dalam Feist dan Feist, 2013) sebagai ketidaksadaran kolektif. Ketidaksadaran kolektif bertanggung jawab terhadap kepercayaan tentang agama, mitos, serta legenda yang dialami oleh individu. Jung (1983) juga mengungkapkan bahwa ketidaksadaran kolektif tidak merujuk pada ide yang diturunkan, tetapi lebih pada kecenderungan kuat manusia untuk bereaksi dengan cara tertentu saat pengalaman menstimulasikan kecenderungan turunan secara biologis. Gagasan primordial dalam ketidaksadaran kolektif muncul dalam diri individu dalam bentuk arketipe. Jung (1983) mengungkapkan bahwa arketipe terbentuk melalui pengulangan pengalaman dari para leluhur yang akan aktif saat pertemuan pengalaman personal dengan bayangan primordial.

Pada masyarakat Gunung Kidul ketidaksadaran kolektif mengenai Pulung Gantung kemudian menjadi sebuah kondisi psikis potensial yang dikaitkan dengan fenomena-fenomena mistis terkait bunuh diri. Isi dari ketidaksadaran kolektif ini secara aktif dapat mempengaruhi pikiran, emosi, dan perilaku seseorang termasuk salah satunya adalah perilaku bunuh diri di Gunung Kidul. Hal ini selaras dengan hasil wawancara yang dilakukan oleh penulis dengan beberapa masyarakat Gunung Kidul yang menghasilkan temuan bahwa Pulung Gantung selalu muncul ketika akan ada orang-orang yang melakukan gantung diri. Beberapa masyarakat bahkan mengaku pernah menjumpai penampakan Pulung Gantung dan menggambarkannya dalam bentuk bola api yang memiliki ekor dan terbang mengitari rumah masyarakat. Setiap kali Pulung Gantung muncul, masyarakat Gunung Kidul selalu mengasosiasikan kemunculan tersebut sebagai pertanda buruk seperti akan ada orang yang bunuh diri atau musibah yang akan menimpa masyarakat Gunung Kidul. Fenomena ini sama dengan yang disebut Jung (1983) sebagai arketipe spirit. spirit merupakan gambaran primordial mengenai semua hal yang bersifat sesuatu yang imateri (tidak memiliki bentuk fisik) seperti Tuhan, roh-roh leluhur, serta roh jahat. Kaitan antara arketipe spirit dan perilaku individu seringkali tidak dapat dilihat secara langsung karena spirit dianggap berada pada tingkat yang lebih tinggi daripada fenomena psikis dan fisik yang dapat teramati. 


\section{Kesimpulan Dan Saran}

\section{Kesimpulan}

Kasus bunuh diri yang sering terjadi di Gunung Kidul tidak selalu disebabkan oleh Pulung Gantung . Seperti pada kasus percobaan bunuh diri pada P1 dan P2 yang disebabkan oleh beberapa masalah yang mendahului. Masalah hutang, penyakit menahun, serta keengganan menceritakan masalah kepada keluarga menjadi pemicu utama munculnya tindakan bunuh diri. Percobaan bunuh diri yang terjadi pada partisipan dilakukan dengan tidak sadar. Pada P1 proses hilangnya kesadaran terjadi setelah ia mendapat ajakan dari anaknya yang telah meninggal. Pada P2, proses hilangnya kesadaran terjadi setelah ia mendengar bisikan yang tidak dikenalnya.

Percobaan bunuh diri ini tentunya membawa dampak bagi partisipan. Baik P1 dan P2 menunjukkan adanya perubahan yang positif pasca percobaan bunuh dirinya. Seperti pada P1 yang menjadi lebih dekat serta terbuka kepada keluarga ketika mempunyai masalah. Sementara pada P2 timbul perasaan bersyukur karena berhasil sembuh dari penyakitnya serta dapat kembali beraktivitas pasca percobaan bunuh dirinya.

\section{Saran}

Dalam penelitian ini, peneliti menyadari adanya keterbatasan jumlah partisipan. Untuk penelitian selanjutnya agar menambah jumlah partisipan yang memiliki masalah yang berbeda untuk menambah kedalaman data. Selain itu, data sekunder yang didapatkan oleh penulis mengenai budaya Pulung Gantung belum cukup mendalam.

Untuk masyarakat Gunung Kidul agar bisa membedakan antara mitos dan realita yang terjadi dalam masyarakat, guna mempermudah penanganan individu yang mendapatkan masalah agar angka bunuh diri di Gunung Kidul dapat berkurang.

Oleh karena faktor ekonomi dan kesehatan fisik dan psikis merupakan faktor kunci dari studi ini yang berkaitan dengan percobaan bunuh diri, maka Pemerintah setempat serta lembaga yang bergerak dalam pemberdayaan masyarakat bisa lebih focus pada kesulitankesulitan sepereti ini yang kemudian mudah memicu orang untuk melakukan bunuh diri atau upaya pencobaan bunuh diri dalam konteks kultural Pulung Gantung yang sudah menjadi mitos setempat.

\section{Daftar Pustaka}

Agung, D.H. (2017, Maret 17). Facebook sediakan layanan untuk cegah bunuh diri. Tirto.ID. https://tirto.id/facebooksediakan-layanan-untuk-cegah-bunuh-diri-ck1k

American Psychiatric Association. (2013). DSM V (Diagnostic and Statistical Manual of Mental Disorders V). American Psychiatric Association.

Amelia, R. (2017, Maret). Kronologi indra live bunuh diri di facebook. https://news.detik.com/berita/d-3450053/kronologi-indra-gantung-diri-live-difacebook?_ga=2.89474395.1944543114.1560931732-664227345.1559923099 
Auditory Hallucinations in Psychiatric Illness. (2010, Maret 10). Psychiatric Times. https://www.psychiatrictimes.com/view/auditory-hallucinations-psychiatric-illness

Barlow, D. H. (2002). Anxiety and its disorders : The nature and treatment of anxiety and panic / David H. Barlow.-2nd ed.

Bappeda Provinsi Yogyakarta. (2016). Jumlah Penduduk DIY.

Bertolote, J. M., \& Fleischmann, A. (2015). A global perspective in the epidemiology of suicide. Suicidologi, 7(2), 6-8.

British Columbia Ministry of Health and Centre for Applied Research. (2007, Desember 06). MHA Cognitive Behavioural Therapy. https://www.health.gov.bc.ca/library/publications/year/2007/MHA_CognitiveBehavio uralTherapy.pd

Darmaningtyas. (2002). Pulung Gantung : Menyingkap Tragedi Bunuh Diri di Gunung Kidul. Salwa Press.

Borges, G., Benjet, C., Medina-Mora, M. E., Orozco, R., \& Nock, M. (2008). Suicide ideation, plan, and attempt in the Mexican adolescent mental health survey. Journal of the American Academy of Child \& Adolescent Psychiatry, 47(1), 41-52.

Coryell, W., Noyes, R., \& House, J. D. (1986). Mortality among outpatients with anxiety disorders. American Journal of Psychiatry, 143(4), 508-510.

During, MD., Elahi., Taieb., Moro, \& Baubet. (2011). A critical review of dissociative trance and possession disorders: Etiological, diagnostic, therapeutic, and nosological issues. Canadian Journal of Psychiatry. Revue Canadienne De Psychiatrie, 56(4): 235-42.

Fitzgerald, J., Galyer, Whiu \& Thomas. (2010). Understanding Families and Suicide Risk. The National Centre of Mental Health Research, Information and Workforce Development.

Foote, B., Neft., Smolin, Y., \& Liptzhit. (2008). Dissociative Disorders and Suicidality in Psychiatric Outpatients. The Journal of Nervous and Mental Disease, 196(1):29-36.

Fujita, J., Takahasi, Y., Nishida, A., Okumura, Y., Ando, S., Kawano, M., Toyohara, K., Sho, N., Minami, T., \& Arai, T. (2015). Auditory verbal hallucinations increase the risk for suicide attempts in adolescents with suicidal ideation. Schizophrenia Research, 168, 209-12.

Ghose, B., Wang., Tang, W., \& Yaya, S. (2019). Engagement in physical activity, suicidal thoughts and suicide attempts among older people in five developing countries. PeerJournal.com.

Girard, C. (1993). Age, gender, and suicide: A cross-national analysis. American sociological Review, 58(4), 553-574.

Harris, M. (2001). The rise of anthropological theory: A history of theories of culture. Altamira Press.

Hooley., Nock \& Franklin. (2014). Chronic pain and suicide: Understanding the association. Current Pain and Headache Reports, 18, 435.

Jung, C.G. (2014). The Collected Works of C.G. Jung : Complete Digital Edition Vol 9 Archetypes and the Collective Unconsciousness. Preceton University Press.

Jung, C.G. (2014). The Collected Works of C.G. Jung : Complete Digital Edition Vol 1-19. Preceton University Press.

Mitos Pulung Gantung dan upaya menangani kasus bunuh diri di Gunung kidul. (2017,September 10). British Broadcasting Corporation Indonesia. https://www.bbc.com/indonesia/indonesia-41194325

Mulyani, A.A., \& Eridiana, W. (2018). Faktor-faktor yang melatarbelakangi fenomena bunuh diri di gunung kidul. Sosietas, 8(2):510-516.

Nepon, Belik \&Bolton. (2010). The relationship between anxiety disorders and suicide attempts: Findings from the national epidemiologic survey on alcohol and related conditions. Depression and Anxiety, 27(9):791-798 • https://doi.org/10.1002/da.20674

Nock, M., Bromet, E., Borges, G., \& Cha, C. (2008). Suicide and Suicidal Behavior. Epidemiologics, 30(1): 133-54. https://doi.org 10.1093/epirev/mxn002

Ohayon, Morselli \&Guilleminault C. (1997). Prevalence of nightmares and their relationship to psychopathology and daytime functioning in insomnia subjects. Sleep, 20:340-348.

O'connor \& Nock. (2014). The psychology of suicidal behaviour. The Lancet Psychiatry, 1(1):7385. 
Öztürk, E \& Sar V. (2008). Somatization as a predictor of suicidal ideation in dissociative disorders. Psychiatry and Clinical Neurosciences, 62, 662-668.

Reider, E.E.\& Sims, B.E. (2017). Family-Based Preventive Interventions: Can the Onset of Suicide Ideation and Behavior Be Prevented?. US National Library of Medicine National Institute of Health, 46:S3-S7.

Rimsh \& Pietrowsky. (2020). Dreams in anxiety disorders and anxiety. International Journal of Dream Research, 13(1):1-8.

Souminen, K., Isometsa, Haukka, \& Lonnqvist. (2004). Levell of suicide intent predict overall mortality and suicide after attempted suicide: A 12-year follow-up study. BMC Psychiatry, 4,(11):1-14.

Study on Correlation between Anxiety Symptoms and Suicidal Ideation Article (PDF Available) in Psychiatry investigation 8(4):320-6 - Desember 2011 with 132 Reads

Suicide risk factors and warning signs. (2015, December 1). American Foundation for Suicide Prevention. https://www.afsp.org/understanding-suicide/suicide-risk-factors

Suicide: Risk and protective factors. (2015, December 1). Centers for Disease Control and Prevention. http://www.cdc.gov/violenceprevention/suicide/riskprotectivefactors.html

Sun F, Norman IJ, \& While AE.(2013). Physical activity in older people: a systematic review. BMC Public Health. 13(1):449.

Tang \& Crane. (2006). Suicidality in chronic pain: A review of the prevalence, risk factors and psychological links. Psychological Medicine, 36, (5):575-86. https://doi.org/10.1017/S0033291705006859

Wirasto, R. T. (2012). Suicide prevention in Indonesia: Providing public advocacy. Japan Medical Association , 55, 98-104.

World Health Organization. (2018). Suicide data. World Health Organization.

Zhai, H., Bai B., Cen, L., Han., D., Wang, L., Qiao, L., Qiu, X., Yang, X., \& Yang, Y. (2015). Correlations between family environment and suicidal ideation in university students in china. International Journal of Environmental Research and Public Health, 12, 14121424. 